\title{
Evaluation of Several Drought Tolerance Criteria in Cultivated Varieties of Barley (Hordeum vulgare L.) and Their Relationships with Yield Reduction
}

\author{
Saeideh Dorostkar, Hassan Paknyiat ", Mahmood Ahmadi Kordshooli, Raziyeh Ghorbani, \\ Massumeh Aliakbari, Neda Sobhanian, Reza Valiloo
}

Department of Crop Production and Plant Breeding, Shiraz University, Shiraz, Iran

\section{Email address:}

Saeideh.dorostkar@gmail.com (S. Dorostkar),pakniyat@shirazu.ac.ir (H. Paknyiat),mahmood.ahmadi93@gmail.com (M. A. Kordshooli), ghorbaniraziyeh@gmail.com (R. Ghorbani),ndsobhanian@yahoo.com (N. Sobhanian), massume.aliakbari@gmail.com (M. Aliakbari), reza.valilo@yahoo.com (R. Valiloo)

\section{To cite this article:}

Saeideh Dorostkar, Hassan Paknyiat, Mahmood Ahmadi Kordshooli, Raziyeh Ghorbani, Massumeh Aliakbari, Neda Sobhanian, Reza Valiloo. Evaluation of Several Drought Tolerance Criteria in Cultivated Varieties of Barley (Hordeum vulgare L.) and Their Relationships with Yield Reduction. Science Research. Vol. 4, No. 2, 2016, pp. 26-32. doi: 10.11648/j.sr.20160402.11

\begin{abstract}
Drought is the most significant constraint for crop production in the world. Therefore, employing high-yielding cultivars tolerant to drought is an effective approach to reduce its detrimental effects. Six barley cultivars were evaluated to screening drought tolerant cultivars in two different conditions of irrigation. The experiments were arranged based on randomized complete block design with three replications at the research station of College of Agriculture, Shiraz University, Shiraz, Iran. The cultivars in the first experiment meet normal irrigation condition (100\% field capacity; FC) while these cultivars in the second experiment were exposed to water-stressed condition (no irrigation after anthesis). Grain yield, its components and drought tolerance indices based on grain yield of the genotypes such as Tolerance (TOL), Mean Productivity (MP), Susceptibility Index (SI), Stress Susceptibility Index (SSI), Geometric Mean Productivity (GMP) and Stress Tolerance Index (STI) were calculated. Analysis of variance showed highly significant differences among the barley cultivars for yield and its components in normal and stress conditions. Yield in non-stress (Yp) and stress (Ys) conditions showed positive and significant correlations with STI, MP and GMP. PCA analysis also indicated that STI, MP and GMP were more reliable indices to screen drought tolerant barley cultivars. The results revealed that Lokht-Himalia and Dorla were sensitive and semi-sensitive, respectively. Other evaluated barley cultivars were tolerant to drought. Therefore, they may be recommended for cultivate in drought prone regions. Also these cultivars can be used in barley breeding programs aimed at improving drought tolerance.
\end{abstract}

Keywords: Drought, Stress, Crop Yields, Tolerance Indices

\section{Introduction}

Barley is one of the most important cereal crops worldwide. It has been cultivated in many parts of the world due to its resistance under adverse environments, such as limited moisture and saline conditions [1]. To evaluate the yield potential and to identify stable and resistant barley cultivars it is needed to consider and screen them in different climatic conditions, low rainfall and inappropriate distribution.

Environmental stresses, especially drought as one of the most major limiting factors, can decrease agricultural production in the world [2]. Plants response against water deficit stress are confounded by several factors such as time, intensity, duration and frequency of stress as well as by plant, soil and climate interactions [3] that based on these cases, morphological, physiological and metabolic changes were performed in all their plants organs [3]. Therefore, selection and development of drought tolerant cultivars is great priority to reduce the adverse effects of drought for more consistent levels of crop production. Breeding for yield improvement under water limited conditions is a more complicated scenario than that of under stress-free conditions $[4,5]$. One of the most common ways to evaluating these cultivars is using of drought tolerance indices based on its grain yield. These indices are either based on drought tolerance or sensitivity of cultivars [6]. 
Alternatively, some breeders have employed statistical parameters to compare grain yield changes under stress and non-stress conditions for the selection of tolerant cultivars [7]. Reference [7] introduced tolerance index (TOL), the yield difference between non-stress (Yp) and stress (Ys) environments, and mean productivity (MP) as the average of Yp and Ys. Based on these indices, genotypes with high MP and low TOL are favored. By suggesting the stress susceptibility index (SSI), Reference [8] showed that genotypes with SSI less than one were tolerant. Reference [6] defined the stress tolerance index (STI) as an advanced index to identify high-yielding genotypes under stress and non-stress conditions based on Yp, Ys and $\bar{Y}$ p (average of total Yp). Alternatively, he suggested the geometric mean productivity (GMP) as another STI which is estimated using the square root of the sum of Yp and Ys. These drought tolerance indices are analyzed by different multivariate statistical approaches to obtain more precise selection indicators for drought tolerance. Significant variation has been found between barley cultivars in terms of response to drought stress [9] and to release the new barley cultivars, it is essential to evaluate their response to water deficit stress, particularly when they are introduced to the regions with limited water resources. The present study was aimed to assess drought tolerance in six barley cultivars using the yield, its components and yield-based indices for breeding programmes.

\section{Materials and Methods}

To evaluate effects of drought stress on grain yield, six barley cultivars were evaluated on a silty loam soil at the research station of College of Agriculture, Shiraz University (1810 $\mathrm{m}$ above mean sea level with longitude $52^{\circ} 32^{\prime} \mathrm{E}$ and latitude $29^{\circ} 36^{\prime} \mathrm{N}$ ), Iran under field condition. Six barley cultivars (Karoon Kavir, Lokht Hymalia, Reyhan, Dorla, Valfajr and Karoon) were compared using a randomized complete block design with three replications in two different irrigation conditions (two different experiments). The cultivars in the first experiment meet normal irrigation condition (100\% field capacity; FC) while these cultivars in the second experiment were exposed to water-stressed condition (no irrigation after anthesis). Barley cultivars were planted in plots with an area of 10 square meter. Each plot consisted of 8 rows, $5 \mathrm{~m}$ long with $25 \mathrm{~cm}$ apart. The cultivars were planted with density of 250 seeds $\mathrm{m}^{-2}$. Weather data at the experimental site are given in Table 1.

Urea fertilizer ( $46 \%$ nitrogen, $300 \mathrm{~kg} \mathrm{ha}^{-1}$ ) was split in two parts and applied at planting and ear-emergence stages along with irrigation water. Weeds were removed mechanically throughout the growing season. Grain yield and its components (Plant Height (PH), Spike Length (SL), Grains number Per Spike (GPS), Thousand Kernel Weight (TKW), Total Tillers (TT), Fertile Tillers (FT)), biological yield (aboveground biomass) and harvest index (HI) were measured by harvesting $2 \mathrm{~m}^{2}$ of the center of each plot. The following yield-based drought tolerance indices were calculated where $\mathrm{Yp}$ and $\mathrm{Ys}$ are grain yield under non-stress and stress conditions, respectively. $\bar{Y}$ p and $\bar{Y}$ s are their overall mean of grain yield under stress and non-stress conditions, respectively.

1) Tolerance: TOL = YP -YS (Rosielle and Hamblin, 1981)

2) Mean Productivity: $M P=(Y p+Y s) / 2$ (Rosielle and Hamblin, 1981)

3) Susceptibility Index: $\mathrm{SI}=1-(\overline{\mathrm{Y}} \mathrm{s} / \overline{\mathrm{Y}} \mathrm{p})$ (Fischer and Maurer 1978)

4) Stress Susceptibility Index: SSI=1-(Ys/Yp) )/SI (Fischer and Maurer, 1978)

5) Geometric Mean Productivity: $\mathrm{GMP}=\sqrt{\mathrm{Yp} \times \mathrm{Ys}}$ (Fernandez, 1992)

6) Stress Tolerance Index: STI $=[(\mathrm{Yp})(\mathrm{Ys})] /(\overline{\mathrm{Y}} \mathrm{p}) 2$ (Fernandez, 1992)

7) $\mathrm{HMP}=(2 \times \mathrm{Yp} \times \mathrm{Ys}) /(\mathrm{Yp}+\mathrm{Ys})($ Fernandez, 1992)

Statistical analyses were performed using SAS 9.3 [10] softwares and means were compared using Duncan's multiple range test at $5 \%$ probability level. Correlation coefficients were calculated to find out the relationships among the indices and the grain yield under both conditions. Based on Principal component analysis, biplot diagram was depicted to identify the high yielding drought tolerant barley cultivars graphically.

Table 1. Some weather parameters of the experimental site during the 2000-2001 growing season.

\begin{tabular}{llllll}
\hline \multirow{2}{*}{ Month } & \multicolumn{2}{l}{ Temperature $\left({ }^{\circ} \mathbf{C}\right)$} & Relative Humidity (\%) & Precipitation (mm) & Daily evaporation average (mm) \\
\cline { 2 - 5 } & Min & Max & 60.55 & 64 & 4.48 \\
\hline November & 1 & 28 & 69 & 83 & 2.09 \\
December & -3 & 21 & 65.17 & 40 & 1.54 \\
January & -4 & 18 & 58.8 & 40 & 0.83 \\
February & -10 & 19 & 58.76 & 24 & 3.28 \\
March & -4 & 22 & 57 & 13 & 5.58 \\
April & 0 & 28 & 44 & 8 & 6.41 \\
May & 5 & 34 & & 0 & 10.34 \\
June & 9 & 37 & & 272 & \\
Total & & &
\end{tabular}




\section{Results and Discussion}

\subsection{Comparison of the Cultivars Yield and Yield Based Indices}

Analysis of variance showed that there is a significant difference among the barley cultivars related to grain yield in stress and normal irrigation conditions (Table 2). The highest value of TOL, $294.4 \mathrm{gm}^{2}$ and SSI, 1.07 was belonged to Kavir. The high values of SSI and TOL show sensitivity to drought stress. Therefore low values of SSI and TOL are important to select high-yielding cultivars under stress condition [7]. Based on these two indices, Kavir and Reyhan had the lowest SSI and TOL indices, respectively (Table 2). Reyhan is considered as a non-tolerant cultivar by the farmers in Iran country. The MP index introduces relatively high-yielding cultivars in non-stress conditions, but low-yielding ones under stress condition. This index is associated with STI, GMP and HM indices and cannot be suitable alone. Hymalia (naked seed) was located in specific group and was the most sensitive one. Dorla was introduced as semi-sensitive one in comparison to cultivars based on STI index. This shows higher efficiency of this index in selecting and grouping cultivars (Table 2).

Table 2. Yield mean and drought tolerance indices of six barley cultivars under stress and non-stress conditions.

\begin{tabular}{|c|c|c|c|c|c|c|c|c|}
\hline Cultivar No. & $Y p\left(g / m^{2}\right)$ & Ys $\left(\mathrm{g} / \mathrm{m}^{2}\right)$ & TOL $\left(\mathrm{g} / \mathrm{m}^{2}\right)$ & SSI & MP & STI & HМ & GMP \\
\hline Karoon Kavir & $431.1 \mathrm{a}$ & $181.8 \mathrm{a}$ & 294.4 & 0.91 & 306.4 & 0.49 & 255.7 & 279.9 \\
\hline Himalia & $247.2 \mathrm{~b}$ & $82.87 \mathrm{~b}$ & 164.3 & 1.05 & 165.0 & 0.13 & 124.1 & 143.1 \\
\hline Reyhan & $479.4 \mathrm{a}$ & $158.1 \mathrm{a}$ & 32.4 & 1.06 & 318.7 & 0.47 & 237.8 & 275.3 \\
\hline Valfajr & $416.6 \mathrm{a}$ & $164.5 \mathrm{a}$ & 252.1 & 0.96 & 290.5 & 0.43 & 235.8 & 261.8 \\
\hline Karoon & $440.4 \mathrm{a}$ & $169.6 \mathrm{a}$ & 270.8 & 0.97 & 304.9 & 0.46 & 244.9 & 273.3 \\
\hline
\end{tabular}

Means with the same letters are not significantly different (Duncan's test at 5\% of probability); TOL: Tolerance Index, SSI: Stress Susceptibility Index, MP: Mean Productivity, STI: Stress Tolerance Index, HM: Harmonic Mean, GMP: Geometric Mean Productivity.

Table 3. Correlation coefficients between $Y p$, Ys and drought tolerance indices in barley cultivars.

\begin{tabular}{|c|c|c|c|c|c|c|c|c|}
\hline Variables & Yp & Ys & STI & HM & GMP & SSI & TOL & MP \\
\hline$Y p$ & 1 & & & & & & & \\
\hline Ys & $0.88^{* *}$ & 1 & & & & & & \\
\hline STI & $0.95^{* *}$ & $0.98^{* *}$ & 1 & & & & & \\
\hline HM & $0.93^{* *}$ & $0.99^{* *}$ & $0.99^{* *}$ & 1 & & & & \\
\hline GMP & $0.96^{* *}$ & $0.98^{* *}$ & $0.99^{* *}$ & $0.99^{* *}$ & 1 & & & \\
\hline SSI & $0.31^{* *}$ & -0.71 & -0.58 & -0.63 & -0.55 & 1 & & \\
\hline TOL & $0.94^{* *}$ & $-0.69^{* *}$ & -0.80 & $0.76^{*}$ & $0.82^{*}$ & 0.02 & 1 & \\
\hline
\end{tabular}

** and *: significant correlation at 1 and 5\% levels of probability respectively; Yp: yield under non-stress condition, Ys: yield under stress condition, TOL: Tolerance Index, MP: Mean Productivity, SSI: Stress Susceptibility Index, GMP: Geometric Mean Productivity, STI: Stress Tolerance Index, and HM: Harmonic Mean.

\subsection{Correlation Analysis}

The contradictory drought tolerance ranking of the cultivars via different indices led to determine more reliable indices to select drought tolerant cultivars. To do so, correlation coefficients between Yp, Ys and drought tolerance indices were calculated (Table 3 ). There were positive significant correlations between Yp and all drought tolerance indices. For example yield under non stress conditions showed a correlation of 0.94 with TOL and 0.98 with MP (Table 3). Ys was also correlated with MP ( $\mathrm{r}=0.94), \mathrm{GMP}(\mathrm{r}=0.98)$, STI $(\mathrm{r}=$ $0.98)$ and $\mathrm{HM}(\mathrm{r}=0.99)$. These correlations explain that genotypes with high values of these indices are superior under both stress and non-stress conditions. These results are in agreement with those reported by references [6] in bean and [11] in wheat who reported that yield under stress (Ys) conditions had positive significant correlations with STI, MP, HM and GMP whereas no significant correlations were observed between Ys and SSI and TOL indices, indicating that these indices were not good indicators to identify the cultivars with high yield potential. These negative correlations between
Ys and SSI and TOL show that genotypes with low value of these indices are more suitable under stress condition, since tolerant genotypes have low value of SSI and TOL and selection based on these indices leads to selecting high-yielding genotypes in stress and low-yielding genotypes in non-stress conditions. Therefore, SSI and TOL are not beneficial in screening tolerant genotypes. Positive significant correlation between STI, GMP, MP and HM under both stress and non-stress conditions indicates their stronger effects over SSI and TOL [12, 13]. Our results were consistent with reference [14] on barley cultivars since they also found positive significant correlations between Yp, Ys, STI, GMP, MP and HM and in other crop species such as rapeseed $[9,15]$, wheat $[16,17,18]$, maize $[19,20]$, and rice [21].

\subsection{Three-Dimensional Diagrams of Drought Tolerance Indices and Grain Yield}

It was realized that STI, GMP, MP and HM indices had stronger effects to screen tolerant cultivars under both stress and non-stress conditions. Based on these result, 
three-dimensional diagrams of each index with grain yield under non-stress condition (Yp) and stress condition (Ys) was plotted (Figure 1). Considering MP index, two groups of cultivars were identified which were consisted of relatively high-yielding cultivars in non-stress conditions and low-yielding ones under stress condition (Figure 1-a). This index can not realize mediated groups. However, it is associated with STI, GMP and HM indices and cannot be effective alone. The highest value of MP belonged to Reyhan. Despite skewed and more susceptibility of MP index in comparison to GMP index (Figure 1-a), it may not be concluded that this cultivar was the most drought tolerant one.

Based on GMP and HM indices (Figure 1-c), cultivars divided to sensitive and resistant groups so that Karoon and Reyhan ranked first and second, respectively in resistant group. Up or down trends of grain yield of cultivars in terms of STI index was similar to GMP. Based on STI index, Hymalia had the lowest value of drought tolerance indices and located in a separate group (figure 1-d). Dorla was classified as a
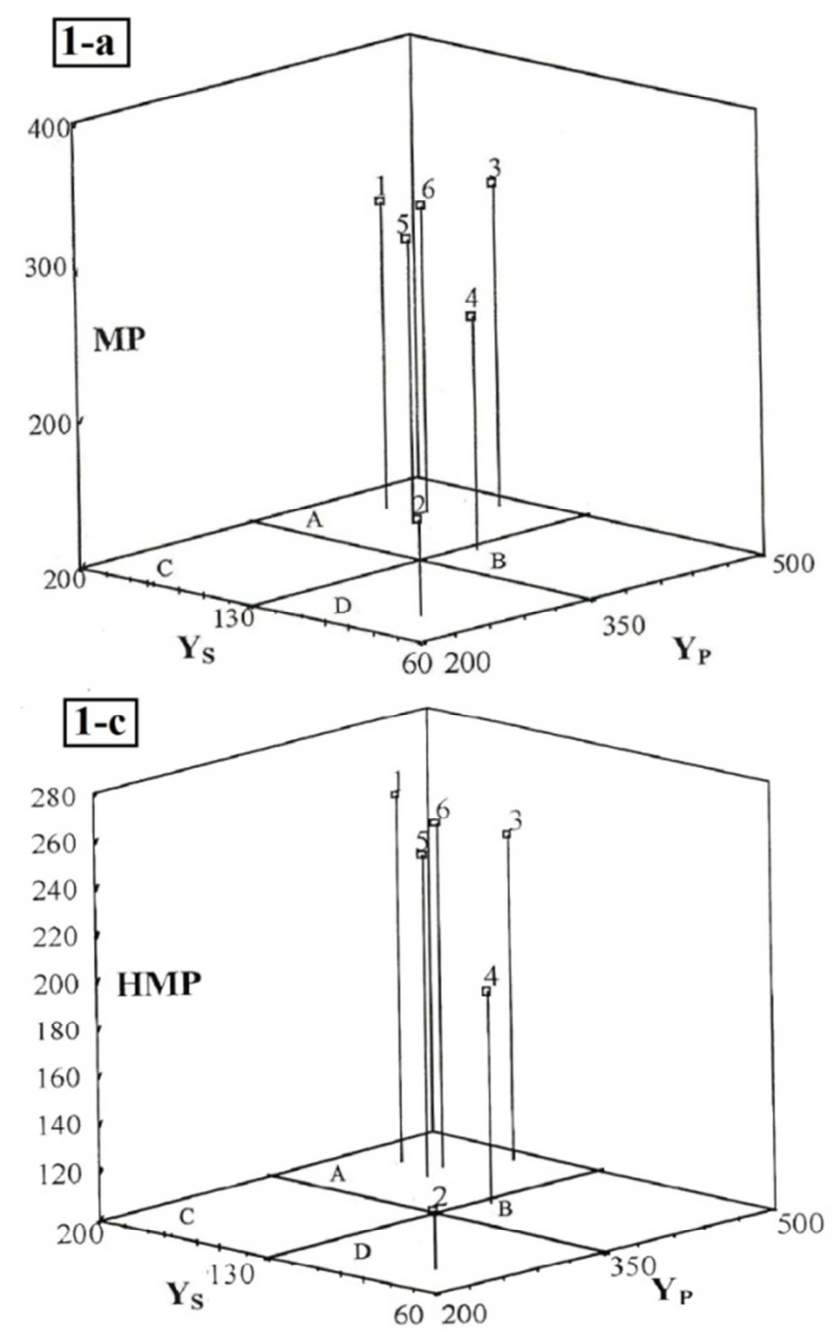

semi-resistant one while it was introduced as a resistant one by other indices and it appeared the efficiency of STI index in comparison to other indices in the differentiation of group A from group B. Hence, cultivars with high values of STI also showed high GMP and HM indices and low values of SSI and TOL while genotypes with low STI showed low values of GMP, MP and HM but associated with high values of SSI and TOL. Therefore, selection based on STI may result in high-yielding tolerant ones (Fernandez 1992). Other researches have also used different indices for selecting tolerant cultivars. For example, reference [22] reported that selection based on a combination of SSI and GMP is more efficient for improving drought tolerance in common bean. Reference [9] selected high yielding corn hybrids based on STI and GMP indices under both stress and non-stress conditions. Reference [23] screened drought tolerant wheat varieties by high values of MP, GMP, STI and low values of SSI under both $100 \%$ and $25 \%$ field capacity conditions and concluded that the cultivar Hashim-8 was drought tolerant.
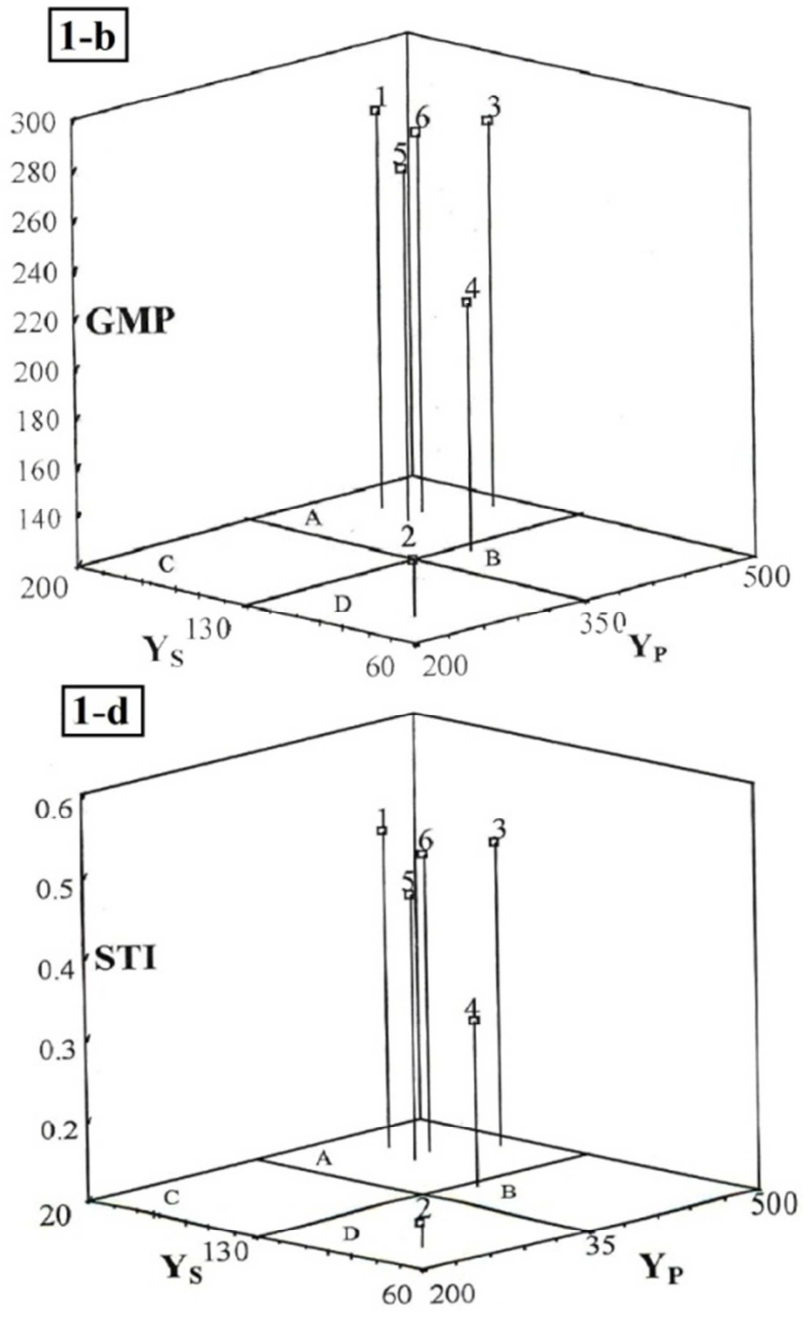

Figure 1. Three-dimensional diagrams of each index with grain yield under non-stress condition and stress condition.

Note: MP: Mean Productivity index, GMP: Geometric Mean Productivity, HMP: Harmonic Mean, STI: Stress Tolerance Index, Yp: Grain Yield under non-stress condition, Ys: Grain Yield under stress condition, number 1: Karoon Kavir, number 2: Hymalia, number 3: Reyhan, number 4: Dorla, number 5: Valfajr, number 6: Karoon 


\subsection{Regression Model of Grain Yield with Yield Components Under Both Stress and Non-stress Conditions}

Stepwise regression was used to obtain the best multivariate regression equation in both experiments (stress and non-stress conditions). In both experiments, yield components and grain yield were considered as independent and dependent variables, respectively. Regression coefficients, $T$ value and significant levels of independent variables were shown in Table 4. According to significant level of independent variables $(\mathrm{p}<$ $0.05)$, the most important independent variables were determined and the following equations were presented, while $\mathrm{Yp}$ and $\mathrm{Ys}$ are grain yield under non-stress and stress conditions, respectively:

$$
\mathrm{Yp}=-339.565+0.474 \mathrm{BY}+7.244 \mathrm{HI}\left(\mathrm{r}^{2}=0.997\right)
$$

$\mathrm{Ys}=-152.326+0.463 \mathrm{BY}+3.49 \mathrm{HI}-1.769 \mathrm{SL}\left(\mathrm{r}^{2}=0.999\right)$

In stress condition, in addition to biological yield and harvest index that were entered into the regression equation of non-stress condition, spike length with a negative impact on grain yield was compiled final equation. This shows the importance of spike length under both stress and non-stress conditions and the effects of stress condition on selection patterns. The high value of determination coefficient in both models was clearly explained the changes of grain yield in plant. Under non-stress condition, R-square explained 99.7\% of total variation of grain yield by two variables (harvest index and biological yield) while under stress condition, spike length via harvest index and biological yield increased R-square and this coefficient was explained $99.7 \%$ of the total variation of grain yield. These results were in agreement with reference [24] who studied abiotic stress tolerance of Iranian barley (Hordeum vulgare L.) genotypes in seedling growth stages and they found significant differences among the genotype $\times$ stress interaction for all characteristics (yield and yield components).

Table 4. Regression coefficients $(\beta)$ and their $T$ value and significant levels related to grain yield as dependent variable under stress and non-stress conditions using stepwise regression.

\begin{tabular}{lllllll}
\hline \multirow{2}{*}{$\begin{array}{l}\text { Dependent } \\
\text { variable }\end{array}$} & \multicolumn{2}{l}{$\begin{array}{l}\text { Regression } \\
\text { coefficients }\end{array}$} & \multicolumn{2}{l}{ T value } & \multicolumn{3}{c}{$\begin{array}{l}\text { Significant } \\
\text { levels }\end{array}$} \\
\cline { 2 - 7 } NS & S & NS & S & NS & S \\
\hline BY & 0.474 & 0.463 & 23.511 & 228.171 & 0.000 & 0.000 \\
HI & 7.244 & 3.490 & 4.700 & 58.271 & 0.018 & 0.000 \\
PH & -0.225 & -0.004 & -2.705 & -0.192 & 0.113 & 0.878 \\
SL & -0.059 & -1.769 & -2.072 & -9.633 & 0.174 & 0.010 \\
GPS & -0.052 & -0.010 & -1.958 & -0.910 & 0.189 & 0.530 \\
TKW & 0.133 & 0.002 & 0.598 & 0.086 & 0.610 & 0.945 \\
TT & 0.067 & 0.032 & 1.823 & 6.330 & 0.210 & 0.099 \\
FT & 0.069 & 0.032 & 1.731 & 4.183 & 0.226 & 0.150 \\
Intercept & -339.565 & -152.326 & -4.919 & -57.149 & 0.016 & 0.000 \\
\hline
\end{tabular}

BY: Biological Yield ( $\mathrm{gr} \mathrm{m}^{-2}$ ), HI: Harvest Index (\%), PH: Plant Height (cm), SL: Spike Length $(\mathrm{cm})$, GPS: Grains number Per Spike, TKW: Thousand Kernel Weight (gr), TT: Total Tillers, FT: Fertile Tillers, NS: Non-stress condition, S: Stress condition.

\subsection{Regression Model of STI Index with Yield and Yield Components Under Both Stress and Non-stress Conditions}

After correlation analysis, STI was determined as one of the best index to screen drought tolerant cultivars. Also, regression model of grain yield showed that biological yield, harvest index and spike length were entered to equations and explained high value of total variation in grain yield. Based on these results, regression model (stepwise) of STI index as dependent variable with yield and yield components as independent variables, was formed under both stress and non-stress conditions as below:

$\mathrm{STI}=-0.349+9.130 \mathrm{BY}$ (under non-stress condition with $\left.\mathrm{r}^{2}=0.956\right)$

$\mathrm{STI}=-0.721+0.129 \mathrm{AT}+0.023 \mathrm{PH}$ (under stress condition with $\mathrm{r}^{2}=0.998$ )

Regression coefficients $(\beta)$, T value and significant levels in stress and non-stress conditions by stepwise regression were shown in Table 5. Under non-stress condition biological yield could explain $95.6 \%$ of total variation, while, fertile tillers and plant height under stress condition reflected $99.8 \%$ of total variation of STI, and other components had insignificant effect on drought tolerant indices. Therefore, those components should be entered to regression equations in breeding programmes that leads to yield increase and drought tolerance. Reference [25] found that barley genotypes significantly differed in plant height, harvest index, biological yield and grain yield. They added that it was possible to identify some barley genotypes that could survive under stress conditions. Hence, regression models of drought tolerance can be used to select stable cultivars in different situations.

Table 5. Regression coefficients ( $\beta$ ), T value and significant levels of STI as dependent variable with yield and yield components as independent variables under stress and non-stress conditions by stepwise regression.

\begin{tabular}{|c|c|c|c|c|c|c|}
\hline \multirow{2}{*}{$\begin{array}{l}\text { Dependent } \\
\text { variable }\end{array}$} & \multicolumn{2}{|c|}{$\begin{array}{l}\text { Regression } \\
\text { coefficients }\end{array}$} & \multicolumn{2}{|c|}{ T value } & \multicolumn{2}{|c|}{$\begin{array}{l}\text { significant } \\
\text { levels }\end{array}$} \\
\hline & NS & $\mathbf{S}$ & NS & $\mathbf{S}$ & NS & $\mathbf{S}$ \\
\hline GY & -0.585 & -0.119 & -0.843 & -0.716 & 0.460 & 0.548 \\
\hline BY & 9.130 & 0.009 & 9.527 & 0.090 & 0.000 & 0.936 \\
\hline $\mathrm{HI}$ & -0.090 & -0.018 & -0.665 & -0.645 & 0.553 & 0.584 \\
\hline PH & -0.126 & 0.023 & -0.226 & 13.827 & 0.835 & 0.000 \\
\hline SL & -0.072 & -0.014 & -0.545 & -0.285 & 0.623 & 0.802 \\
\hline GPS & -0.077 & -0.089 & -0.570 & -1.981 & 0.608 & 0.186 \\
\hline TKW & 0.263 & 0.104 & 0.354 & 0.994 & 0.746 & 0.424 \\
\hline TT & 0.056 & -0.815 & 0.313 & -0.808 & 0.775 & 0.000 \\
\hline FT & 0.058 & 0.129 & 0.308 & 6.071 & 0.778 & 0.009 \\
\hline $\begin{array}{l}\text { Fixed } \\
\text { coefficients }\end{array}$ & -0.349 & -0.721 & -4.492 & -18.439 & 0.010 & 0.000 \\
\hline
\end{tabular}

Note: GY: Grain Yield (gr m $\left.{ }^{-2}\right)$, BY: Biological Yield $\left(\mathrm{gr} \mathrm{m}^{-2}\right)$, HI: Harvest Index (\%), PH: Plant Height (cm), SL: Spike Length $(\mathrm{cm})$, GPS: Grains number Per Spike, TKW: Thousand Kernel Weight (gr), TT: Total Tillers, FT: Fertile Tillers, NS: Non-stress condition, S: Stress condition. 


\section{Conclusion}

Introducing high-yielding drought-tolerant cultivars with early maturity is one of the efficient ways to minimize the effects of drought, which lead to yield loss by reducing TKW and if accompanied with high temperatures after anthesis, hastens whole plant senescence and reduces biological yield and HI in combination, with other water management methods. This study evaluated the level of drought tolerance in six barley cultivars Correlation coefficients revealed that STI, MP, HN and GMP were the most reliable yield-based indices for screening drought tolerant barley cultivars. Among the cultivars, Reyhan, Karoon, Valfajr and Karoon Kavir were known as drought tolerant ones, Dorla and Hymalia were known as semi sensitive and sensitive ones, respectively. Therefore, it can be concluded that breeders can cross the most sensitive and tolerant ones with maximum genetic distance in terms of drought tolerance in breeding programmes aimed at improving drought tolerance in barley. If they consistently show such tolerance over multiple trials, these cultivars may be introduced to cultivate in drought prone regions.

\section{Abbreviations}

FC: Field Capacity; Yp: Grain Yield under non-stress condition; Ys: Grain Yield under stress condition; GY: Grain Yield; BY: Biological Yield; MP: Mean Productivity; GMP: Geometric Mean Productivity; STI: Stress Tolerance Index; SSI: Stress Susceptibility Index; SI: Susceptibility Index; HM: Harmonic Mean; PCA: Principle Component Analysis; TOL: Tolerance Index; GY: Grain Yield; BY: Biological Yield; HI: Harvest Index; PH: Plant Height; SL: Spike Length; GPS: Grains number Per Spike; TKW: Thousand Kernel Weight; TT: Total Tillers; FT: Fertile Tillers.

\section{References}

[1] Ceccarelli, S., Grando, S., \& Baum, M. (2007). Participatory plant breeding in water-limited environments. Experimental Agriculture, 43(04), 411-435.

[2] Chen, R. S., Dilley, M., \& Yetman, G. (2005). Natural. Disaster. Hotspots. A. Global. Risk. Analysis. The World Bank Hazard Management Unit.

[3] Reynolds, M., \& Tuberosa, R. (2008). Translational research impacting on crop productivity in drought-prone environments. Current opinion in plant biology, 11(2), 171-179.

[4] Blum, A. (2005). Drought resistance, water-use efficiency, and yield potential - are they compatible, dissonant, or mutually exclusive?. Crop and Pasture Science, 56(11), 1159-1168.

[5] Pinto, R. S., Reynolds, M. P., Mathews, K. L., McIntyre, C. L., Olivares-Villegas, J. J., \& Chapman, S. C. (2010). Heat and drought adaptive QTL in a wheat population designed to minimize confounding agronomic effects. Theoretical and Applied Genetics, 121(6), 1001-1021.

[6] Fernandez, G. C. (1992, August). Effective selection criteria for assessing plant stress tolerance. In Proceedings of the international symposium on adaptation of vegetables and other food crops in temperature and water stress (pp. 257-270).

[7] Rosielle, A. A., \& Hamblin, J. (1981). Theoretical aspects of selection for yield in stress and non-stress environment. Crop Science, 21(6), 943-946.

[8] Fischer, R. A., \& Maurer, R. (1978). Drought resistance in spring wheat cultivars. I. Grain yield responses. Crop and Pasture Science, 29(5), 897-912.

[9] Khalili, M., Naghavi, M. R., Aboughadareh, A. P., \& Talebzadeh, S. J. (2012). Evaluating of drought stress tolerance based on selection indices in spring canola cultivars (Brassica napus L.). Journal of Agricultural Science, 4(11), p78.

[10] SAS. (2013). SAS version 9.2. Cary (NC): SAS Institute Inc. SAS Online Doc 913.

[11] Reynolds, M. P., Pierre, C. S., Saad, A. S., Vargas, M., \& Condon, A. G. (2007). Evaluating potential genetic gains in wheat associated with stress-adaptive trait expression in elite genetic resources under drought and heat stress. Crop Science, 47(Supplement_3), S-172.

[12] Mardeh, A. S. S., Ahmadi, A., Poustini, K., \& Mohammadi, V. (2006). Evaluation of drought resistance indices under various environmental conditions. Field Crops Research, 98(2), 222-229.

[13] Geravandi, M., Farshadfar, E., \& Kahrizi, D. (2010). Evaluation of drought tolerance in bread wheat advanced genotypes in field and laboratory conditions. Seed and Plant Improvment Journal, 26(2), 233-252.

[14] Nazari, L., \& Pakniyat, H. (2010). Assessment of drought tolerance in barley genotypes. J. Appl. Sci, 10(2), 151-156.

[15] Yarnia, M., Arabifard, N., Khoei, F. R., \& Zandi, P. (2013). Evaluation of drought tolerance indices among some winter rapeseed cultivars. African Journal of Biotechnology, 10(53), 10914-10922.

[16] Dorostkar, S., Dadkhodaie, A., \& Heidari, B. (2015). Evaluation of grain yield indices in hexaploid wheat genotypes in response to drought stress. Archives of Agronomy and Soil Science, 61(3), 397-413.

[17] Farshadfar, E., Poursiahbidi, M. M., \& Safavi, S. M. (2013). Assessment of drought tolerance in land races of bread wheat based on resistance/tolerance indices. International Journal of Advanced Biological and Biomedical Research, 1(2), 143-158.

[18] Aliakbari, M., Saed-Moucheshi, A., Hasheminasab, H., Pirasteh-Anosheh, H., Asad M. T., \& Emam Y. (2013). Suitable stress indices for screening resistant wheat genotypes under water deficit conditions. International Journal of Agronomy and Plant Production, 4(10), 2665-2672.

[19] Naghavi, M. R., Pouraboughadareh, A., \& Khalili, M. (2013). Evaluation of drought tolerance Indices for screening some of corn (Zea mays L.) cultivars under environmental conditions. Notulae Scientia Biologicae, 5, 388-393.

[20] Pakniyat, H., Saed-Moucheshi, A., \& Haddadi, M. H. (2013). Modelling and determination of relationship between kernel yield and its related traits in maize inbred lines and their hybrids using multiple regression and path coefficient analysis. International journal of Agriculture and Crop Science, 5(5), 522-528. 
[21] Rahimi, M., Dehghani, H., Rabiei, B., \& Tarang, A. R. (2013). Evaluation of rice segregating population based on drought tolerance criteria and biplot analysis. International Journal of Agriculture and Crop Sciences, 5(3), 194.

[22] Ramirez-Vallejo, P., \& Kelly, J. D. (1998). Traits related to drought resistance in common bean. Euphytica, 99(2), 127-136.

[23] Khakwani, A. A., Dennett, M. D., \& Munir, M. (2011). Drought tolerance screening of wheat varieties by inducing water stress conditions. Songklanakarin J. Sci. Technol, 33(2), 135-142.

[24] Taghipour, F., \& Salehi, M. (2008). The study of salt tolerance of Iranian barley (Hordeum vulgare L.) genotypes in seedling growth stages. Bio. Diver. Conser, 172, 53-58.

[25] Ahmed, I. A., El-Hag, A. A., Amer, K. A., El-Moselhy, M. A., $\&$ Said, M. A. (2001). Evaluation of some barley genotypes for salt tolerance. National Coordination Meeting, Egypt, ARC, Cairo, Sept., 2-4. 